\title{
Synergistic effect of joining process and its measurement
}

\author{
Anna Polednáková, 1 \\ ${ }^{1}$ EU v Bratislave, Department of Corporate Finance, 85235 Bratislava, Slovakia.
}

\begin{abstract}
Rapid technological advances, globalization is leading to intensified global competition. In order to remain competitive and strengthen their market position, companies often opt for an external growth strategy through M\&A. The most frequently mentioned reason for merging companies to achieve a synergistic effect. For this reason, it is essential that the buyer assesses the potential concentration in order to create value for shareholders. This paper focuses on analyses and characteristics and definition of synergy effect, analysis of main sources of synergy, definition of key variables in assessment of synergies.
\end{abstract}

\section{Introduction}

The technological advances, globalization is leading to intensified global competition. In order to maintain their competitiveness and strengthen their market position, companies often choose a strategy for external growth through mergers and acquisitions.

Mergers and Acquisitions [1] is a broad and challenging subject, as evidenced by a number of professional publications, studies conducted in business practice and the existence of a large number of consulting, financial and investment firms engaged in merger consultancy.

By merging with another business, they gain quick access to new technologies, markets, qualified human resources, built distribution channels, loyal customers and many other sources of future growth. The result of these processes is the emergence of financially strong enterprises. By contrast, companies in financial difficulty are trying to avoid bankruptcy by merging with another company.

It can be said that there is no industry in the world economy where there would be no mergers and acquisitions. [2] The synergy effect can be simply expressed as the fact that the combined effect of two or more activities is greater than their sum.

Methodology. Several scientific methods were used to process the present paper, both from the group of general logical methods and from the group of empirical and exact methods. The method of analysis was used in the examination of theoretical knowledge and opinions on the issue of the synergy effect of merging companies. We used the synthesis method to formulate conclusions synthesizing knowledge from the literature. Other methods used were induction, deduction and comparison. We used the abstraction method to define the essential characteristics of the examined phenomena - synergistic effects. Generalization

${ }^{1}$ Corresponding author: anna.polednakova@euba.sk 
is a method of defining the context of real subjects and has been used to formulate conclusions. The paper was also based on the results of research by both foreign and domestic authors, especially in the area of merging companies and their motives.

\section{Definition of synergy}

Merger and acquisition synergies are an effect that adds value to two [3] or more companies when merged over the separate values of those companies. The concept of synergy is defined, according to the Cambridge dictionary [4], as follows: "Synergy is the combined power of a group of things which, when working together, achieve a higher overall strength than that achieved by the individual components separately"

The term synergy is usually associated with physical science as an economy. It refers to the type of reaction that occurred when combining two factors gives a higher effect than when the sum of two operational independent units is like the sum. The anticipated existence of synergies allows companies to incur the cost of the acquisition process and can still afford a premium for their target shareholders. Synergy is an increase in the performance of the combined company over what is already expected of the two companies or needs to be achieved as independent companies. Achieving synergy begins with a clear understanding of what it is. Defining synergies as "a combination of enterprises of which two plus two equals five" or "the amazing benefits of integration from combined strategies and economies of scale" is inaccurate and misleading.

Mark L. Sirower [5] in his book "Synergy Trap" gives the following definition of synergy. If the acquirers can achieve the performance that is already expected from the objective, the net present value (NPV) of the acquisition strategy is then clearly expressed by the following formula: NPV = Synergy - Premium "

Mergers and acquisitions synergies represent an effect that increases the value of two or more companies when merged over the separate values of these companies. Synergies can result from mergers and acquisitions through cost savings due to improved operational efficiency and / or revenue gains due to increased productivity in the use of company assets. The main objective of merger and acquisition companies is to achieve a synergistic effect. This effect is most objective and is assessed by increasing the value of the investment. The value of the company after the transaction is increased in case of synergies, whether profit or loss. Better financial results and higher business performance are achieved through proper investment selection and proper cost management.

Thus, the buyer usually approaches the assessment of the potential merger and acquisition target in a similar way to the choice of investment or investment project. The Company usually analyses the potential added value of the target company, which in practice uses primarily the net present value (NPV) of future projected cash flows, which are discounted by a discount factor. In practice, inputs to the projected cash flow calculation are adjusted to best predict cash flows for the future period analysed.

At the same time, Sirower [5] describes the cornerstones of synergy as the four elements of the strategy, in merging companies that need to be put in place to achieve a synergistic effect. The cornerstones of synergy include:

- Strategic vision,

- Operational strategy,

- Operational strategy,

- Power and culture.

The buyer usually allows the competitive advantages of the combined enterprise, including increased revenue, reduced costs or technological improvements over the performance of individual entities. So, the synergistic value is usually created by the buyer. 
However, there are exceptions. If the objective has a technology or ownership that the buyer can customize and exploit on its larger volume basis, this "backscatter" synergy is mainly generated by retailers. There are two types of synergy: operational synergy and financial synergy. Operational synergy also takes two forms: increasing revenue and reducing cost.

These revenues and effective profits are derived from vertical or horizontal mergers. Financial synergy refers to the possibility that capital costs may be reduced by a combination of one or more companies.

Operational synergy in the form of returns is very difficult to achieve. Analyses [6] indicate that $70 \%$ of mergers will not achieve operational synergies in the form of revenue increases. Increasing revenue can take several forms:

- price power,

- combination of functional forces,

- growth from fast-growing or emerging markets.

Financial synergy reflects the impact of mergers and acquisitions on the cost of the acquiring company or partners in mergers and acquisitions. Depending on the extent to which financial synergy exists in various combinations in companies, then capital costs may be lower. A merger of two companies may reduce the risk if the company's cash flow is not correlated perfectly.

\subsection{Sources of synergy}

Synergistic benefits [3] generally arise from five possible sources:

- Increase revenue,

- Cost reduction,

- Improvement of processes in society,

- Financial efficiency,

- Risk reduction.

Revenue gains may be the result of higher unit sales, which are usually achieved by a combined entity operating in a wider market or offering an extended product line or both. An increase in the price of products can be achieved, especially if the combined unit creates strategic advantages, for example, that it is the only supplier of technology or product. The projected increase in revenue should be considered with caution as it depends on many external variables, in particular the response of customers and competitors. Both can be difficult to predict and are largely outside the control of the combined unit. For example, customers may have a policy that prevents excessive reliance on any source of supply. A competitor's response should also be envisaged, including new product offers and price discounts. An increase in revenue can be achieved when the combined company offers a wider range of products or services, often by using the new entity's distribution system.

Estimates of the second source of synergy, cost reductions, tend to be more predictable and more reliable than revenue increases. The consolidation of functions eliminates positions and related fixed assets and overheads. The scope of this advantage tends to be greater if the objective is similar to the acquirer in the operations and markets served. Particular attention needs to be paid in advance in order to succeed with cost savings. In particular, wages and salaries require vigilance because, while jobs may be reduced, individuals who held them sometimes survive in a new entity in another department or job.

Process improvements occur when the combined entity adopts more efficient procedures used by the target acquirer. These improvements often result from technological or process improvements that can be utilized on the wider base of the combined unit. Improvements can 
lead to revenue gains or cost reductions, as well as more efficient operations or more efficient marketing and distribution.

The fourth source of synergy, financial efficiency, is often misunderstood. The value of the target cannot be increased by allocating it lower capital costs through the use of debt financing. Since any acquirer could achieve this advantage, such financial manipulations rarely have any real value creation potential. However, the combination may reduce the financial cost of the combined entity and may allow efficiency in terms of lease, cash management and working capital management. The combined entity may also generate certain tax benefits. Acquirers should be aware that financial performance is not capable of substantially improving the company's strategic position and is rarely the driving force behind transactions to bring companies together.

The target cost of capital can be reduced through the acquisition of a larger company that eliminates many of the risks that exist when the company operates independently. A taller company can eliminate several of the risks that typically occur in smaller companies - such as key personality, customer concentration, pace of technological change, and position compared to its competitors - by becoming a segment of a broad-based company markets.

\subsection{Key variables in assessing synergies}

In assessing the potential savings from each of these synergistic sources, the merger management should concentrate mainly on three variables, which can significantly affect the accuracy of the estimated synergy and value calculation significantly.

The magnitude of the benefits of synergy. The value of the synergy should be quantified in the net cash flow forecast, which includes estimates of income, costs, financing and taxes and investments in working capital and fixed assets. Every component of the forecast, in particular any estimated improvements, must be questioned consistently. The management of the acquisition team [6] must resist the natural effort to make emotional purchases, which often leads to overly optimistic revenue and expenditure estimates. Each element in the forecast must be accurately estimated.

The probability of achieving synergy. The merger will bring various benefits, some of which have a very high probability of success, while others may have negative consequences $[7,8,9]$. For example, the probability that the administrative costs associated with the target group board can be excluded is approximately $100 \%$. Conversely, the achievement of certain sales targets against fierce competition is likely to be much less clear-cut. These differences should be recorded and taken into account in the forecast. Calculation of the probability of different results, for example optimistic, expected and pessimistic, can be done using sensitivity analysis, Monte Carlo simulation, helping to quantify the range of possible

Timing the benefits of synergy. Merger and acquisition buyer management needs to recognize that, while an acquisition is usually a single transaction, its benefits accrue over an estimated period of time, which may span many years. The value of the acquisition and its success are critically linked to achieving improved cash flows according to the expected timing. Any delays move cash flows further into the future and reduce their present value. Attempts to accelerate the timing of revenue improvements or cost savings should be avoided, and the timing of each assumption must be questioned as sums. The history of mergers and acquisitions is full of stories about how unrealistic acceleration of improvements to increase the attractiveness of an acquisition has led to an overestimation of the synergy value.

The clear point is to emphasize the importance of objectivity and diligent due diligence in examining the foreseen synergies. Investors expect to improve the performance of the acquirer as well as the target value they set for each company as separate entities. Acquisition-related synergies must reflect improvements beyond those already foreseen. The 
value of these synergies must exceed the premium above the fair market value of the acquirer in order to create value. Therefore, any envisaged synergy must be thoroughly analysed in terms of the estimated amount, likelihood of achievement and when this benefit will occur. Companies that overlook this process may experience unpleasant surprises and disappointments in the future.

\section{Results and Discussions}

Companies that want to survive in a competitive environment must choose a strategy to achieve their goal. One such strategy is mergers and acquisitions. Many companies neglect to prepare the merger process. The main reasons are its complexity, slowness and time preferences of the managers' subjective opinions on the percentage of official controls transactions that refuted the misconception about the success of the executed transaction. Merger and acquisition problems are underestimated by the lack of preparation and underestimation of some important aspects of the process. The result may be quite the opposite of that expected from such an operation. Instead of improving the company's position, efficiency and profitability, there may be a loss of efficiency, inflexibility and loss of competitiveness. In spite of all the risks that Mergers and Acquisitions face, there are thousands of business connections worth billions of euros worldwide each year.

The main motivation for merging and acquiring companies is to achieve a synergistic effect. This category was the subject of our research. Mergers and acquisitions companies must take into account the fact that each merger is something special and must be given particular attention. Achieving synergy begins with a clear understanding of what it is. Defining synergies as "a combination of enterprises of which two plus two equals five" or "the amazing benefits of integration from combined strategies and economies of scale" is inaccurate and misleading.

Thus, the buyer usually approaches the assessment of the potential M\&A target in a similar way to the choice of investment or investment project. The company usually analyses the potential added value of the target company. In order to properly evaluate the choice of investment, it is necessary not only to address the issue of financial synergy (cost of capital), but also operational synergies related to increasing revenues / reducing costs. Assessing synergies in merging companies is essential to analyse this process through key factors that significantly affect the accuracy and accuracy of the estimated synergies.

This work was supported through the Slovak Science Foundation (VEGA) under projects VEGA $1 / 0007 / 19$ "Asset allocation in a low interest rate environment in the financial and non-financial companies in the Slovak Republic".

\section{References}

1. A.P. Gaughan. Mergers, Acquisitions, and Corporate Restructurings. 5th ed Willey, 2010. s.230-236. ISBN 10:0470561963 (2010)

2. N. G.Greg, I. Renneboog. International Mergers and Acquisitions Activity Since 1990: Recent Research and Quantitative analysis. Academic press, Elsevier, MA, USA ISBN 978-0-7506-8289-3 (2007)

3. CH.M. Mellen, F.C. Evans. Building Value in Private Companies. John Wiley and Sons, Inc. ISBN 978-0-470-60441-0 (2010) 
4. D. Schweiger, N.E. Csiszar, N.K.Napier. A strategic approach to implementing mergers and aquisition, The Management of Corporate acquistions, N.Y. (1994)

5. M.L. Sirower. The Synergy trap: How Companies Lose the Acquistion Game (New York: The Free press, 1997,2000), p. 20-29 (2000).

6. S.Sudarsanam. Creating value from mergers and Acquisitions. Harlow, England: Pearson Education limited, (2010).

7. R.Thomson, S. Dettmar, M.Garay, (2020, 19 March). The state of the deal: MERGER AND ACQUISITION TRENDS 2019. Retrieved from https://www2.deloitte.com/us/en/pages/mergers-and-acquisitions/articles/ma-trendsreport.html [cit.20.12.2018].

8. Cambridge Dictionary, (2020, 21 March). Synergy. Retrieved from https:/dictionary.cambridge.org/dictionary/english/synergy?fbclid=IwAR2MaabCldB ZnTwzxY7pzPsvthbaXrLbu1hjHYjPt13GS-zi3ep2HIXX0So

9. Corporate Finance Institute, (2020, 25 March). Types of Synergies: The different sources of synergies.

Retrieved from https://corporatefinanceinstitute.com/resources/knowledge/valuation/types-ofsynergies/?fbclid=IwAR2iQvsAFxOb8K4FuWeMnkCBkRlsM0u8JhovwOcYMt8kxVaI1dcScYib5A 